\title{
Exogenous Polyamine Treatment Prevents UV-A Induced Cellular Damage and Photoinhibition of Photosystem II in Lichen Physcia semipinnata (J. F. Gmel.) Moberg
}

\author{
Dilek Ünal $^{1}$, İnci Tüney Kızılkaya ${ }^{2 *}$ \\ ${ }^{1}$ University of Bilecik, Faculty of Science and Literature, Department of Molecular Biology and Genetics, Bilecik, \\ Turkey \\ ${ }^{2}$ Ege University, Faculty of Science, Department of Biology, Bornova, Izmir \\ *inci.tuney@ege.edu.tr
}

Received: 28 March 2018

Accepted: 06 November 2018

DOI: $10.18466 /$ cbayarfbe.410546

\begin{abstract}
In this study the protection ability of polyamines on Photosystem II (PSII), the proline content of the cells and necrosis formation induced by Ultraviolet-A irradiation were studied. Although $24 \mathrm{~h}$ Ultraviolet-A exposure decreased the photosynthetic quantum yield (Fv/Fm) ratio in Physcia semipinnata (J. F. Gmel.) Moberg, thalli that treated with $1 \mathrm{mM}$ polyamine, especially spermidine and spermine, were slightly influenced by the UV-A exposure. It was also found that spd and spm treated samples had lower proline content than putrescine (put)-treated samples. Moreover, It was found that the samples that were treated with spd and spm had lower percentage of DNA damage than put-treated samples and non-treated groups. In this study, Ultraviolet-A induced DNA damage detected by acridine orange/ethidium bromide staining assay. The DNA damage in thalli of $P$. semipinnata was detected in situ in phycobiont layer after $24 \mathrm{~h}$ of Ultraviolet-A exposure, in contrast, polyamine-treated samples had a lower rate of necrotic cells.

Keywords: Polyamine, photosystem II, proline, Ultraviolet-A, lichen.
\end{abstract}

\section{Introduction}

After the discovery of the severe depletion of the stratospheric ozone, the studies increased about the potential effects of enhanced UV-A (315-400 nm) radiation on all living organisms. The detrimental effects of UV are varied and well known now. Some of these effects are reduction in photosynthesis, increase of growth rate and cell differentiation also damages in the protein contents of PSII and chlorophyll a synthesis, increase in lipid peroxidation, chlorophyll photobleaching, phycobiliprotein degradation, and direct damage on DNA. DNA lesions such as strand breaks are one of the most dangerous damage since they disrupt the linear structure of the DNA and prevent replication and gene expression. In addition, UV radiation generates oxygen and hydroxyl radicals that react with DNA to form monomeric photoproducts such as cytosine and thymine photohydrates and causes strand breaks and DNA-protein crosslinks. The most important toxic and mutagenic photoproducts produced as a result of UV-induced DNA damage is the cyclobutane dimmers. In response to such damages, the cell adapts itself by possessing several strategies such as photoreactivation, nucleotide excision repair and recombination repair in order to remove the photoproducts. A failure in repairing the damage could lead mutations or general deterioration of cell function.
UV radiation affects photosynthetic systems by two ways. It may cause a direct damage on key components such as D1 protein of PS II, so that the photosynthetic pigments are break down or by inhibiting the activation of RUBISCO [1]

Most organisms developed some strategies to avoid these UV-damages. Plants have efficient damage repair mechanisms, such as, rapid repair of the photosynthetic machinery and a variety of other UV-stress responses including UV stress proteins. Often, microalgae produce myosporin-like amino acids (MAAs), an effective UV sunscreen compound that absorbs harmful UV rays to prevent UV-induced damage [2]. Besides MAAs, other pigments such as carotenoids, scytonemines and usnic acides have important photoprotective role against UV damages. Especially carotenoids, scavenge toxic oxygen species formed in the chloroplast. Scytonemins are specific to cyanobacteria and cyanobacteria associated lichens while usnic acid is a lichen specific compound. Similar to MAAs, the synthesis of scytonemins and usnic acid are triggered by UV radiation since the main role of this compounds is UV protection.

Polyamines (PAs) are the other group of molecules play an important role in regulating the sensitivity and the tolerance of organisms under stress conditions. PAs are low-molecular weight polycationic compounds at 
physiological $\mathrm{pH}$. Their binding ability to negatively charged molecules, such as nucleic acids, proteins, and membrane phospholipids [3] protects these vital cell components against stress-induced damage. Diamine put, triamine spd and tetramine spm are the main PAs found in all living cells. Kramer et al. [4] demonstrated the important role polynamines in the plant protection mechanisms during UV-B radiation exposure. Kotzabasis et al. [5] also mentioned the similar findings of their study by reporting the association of spm, spd and put with light harvesting complex (LCH) and the PSII.

Lichen-like organisms exist about 600 million years when the UV-B radiation had reached to earth's surface, and they must already then have developed efficient mechanisms for protection and repair. Studies on the $\mathrm{UV}$ radiation effects and the protection mechanisms against UV-induced stress are increasing, our knowledge about avoidance mechanisms of lichens is still restricted. Furthermore, there is scarce information on other mitigation mechanisms and the role of external polyamines on cell damage of lichens induced by UV-A radiation.

First aim of the present study is to determine the timeand irradiance- relationships of UV-A damage on thalli of $P$. semipinnata. Second aim is to investigate if there is a protective feature of the polyamines on cell damage, regulation effect on the rate of photosynthetic quantum yield and proline accumulation.

\section{Materials and Methods}

\subsection{Lichen Material}

$P$. semipinnata samples were collected from the tree branches in Karagöl (Izmir-Turkey) (38 $33^{\prime}$ N $27^{\circ} 13^{\prime}$ E, $840 \mathrm{~m}$ ) in September. After collection, samples were transferred to the laboratory, cleaned from contaminants and dust by washing three times with distilled water. All the experiments, including UV-treatment conducted under light with intensity of $120 \mu \mathrm{mol} \mathrm{m}^{-2} \mathrm{~s}^{-1}$.

\subsection{UV-A radiation treatment}

Experiment consists of two parts. In the first experiment thalli were exposed to UV-A (Black Ray, $352 \mathrm{~nm}, 50$ $\mathrm{Hz}, 0.60$ Amps, model;XX-20BLB), intensity $\mathrm{J} / \mathrm{cm}^{-2}$, in petri dishes for $1 \mathrm{~h}, 2 \mathrm{~h}, 3 \mathrm{~h}, 5 \mathrm{~h}$ and $24 \mathrm{~h}$ without any treatments. UV-A lamps FSX24T12-UVB-HO, Philips) fixed $15 \mathrm{~cm}$ above the samples. Temperature was stabilized at $24^{\circ} \mathrm{C}$ and checked constantly to avoid heat effects. One thallus was not exposed to UV-A (as negative control).

\subsection{Polyamine Treatment}

After determining the most harmful UV-exposure duration the second part of the experiment carried out. In this experiment $P$. semipinnata thalli were incubated with $1 \mathrm{mM}$ of polyamines, put, spd and spm for 30 minutes. After incubation, thalli were exposed to UV-A radiation in Petri dishes for $24 \mathrm{~h}$.

\subsection{Chlorophyll a fluorescence}

Chlorophyll $a$ fluorescence was measured with the plant efficiency analyzer (Handy PEA, Hansatech). Before measurement, Lichen thalli were dark-adapted for 15 min before measurements. The Fv/Fm (maximum quantum yield efficiency of PSII) parameters were calculated by the fluorescence induction curves of 5 seconds durations recorded at an irradiance of 1800 $\mu \mathrm{mol} \mathrm{m} \mathrm{m}^{-2} \mathrm{~s}^{-1}$ from light emitting diodes. The Fv/Fm parameter was used as a stress indicator by determining the photosynthesis rate. Each treatment was repeated ten times.

\subsection{Proline Analysis}

Proline content was measured by modified method of Bates et al [6]. $0.5 \mathrm{mg}$ tissue of lichen homogenized in $3 \%(\mathrm{v} / \mathrm{v})$ sulfosalicylic acid and homogenate keep in laboratory condition for $24 \mathrm{~h}$. The homogenates filtered through six layers of cheeseclothes. Extracts were treated with acid-ninhydrin at $90^{\circ} \mathrm{C}$ for an hour in water bath. After incubation the tubes transferred to ice boxes to end the reaction. After termination the solution extracted in toluene. Absorbance recorded at $520 \mathrm{~nm}$. in spectrophotometer (Pharo 300, Merck). Absorbance values were calculated by using the standard curve.

\subsection{Tissue section preparation}

The thallus was chopped and fixed in $\% 4$ paraformaldehyde for overnight. The fixed samples were dehydrated in 5 different dilutions $(50 \%, 70 \%$, $80 \%, 95 \%$, and $100 \%$ ) of ethanol for $15 \mathrm{~min}$. The dehydrated samples were dipped into ethanol-xylene (1:1) for $10 \mathrm{~min}$ and in $100 \%$ xylene for $10 \mathrm{~min}$, respectively. The samples were embedded in paraffin, and sectioned in $5 \mu \mathrm{m}$ coarseness via Lecia RM 2145 microtome.

\subsection{Fluorescence microscopy}

Thallus sections were stained with acridine orange (AO)-ethidium bromide (EB) dye solution $(0.01 \%$ $(\mathrm{w} / \mathrm{v})$ acridine orange and $0.01 \%(\mathrm{w} / \mathrm{v})$ ethidium bromide dissolved in $10 \mathrm{mM}$ PBS buffer, $\mathrm{pH}$ 7.0) for 10 min. Olympus BX-51 light microscope equipped with blue fluoresce filters used for microscopy and photographed with an Olympus C-5050 digital camera connected to microscope. Fluorescence activities of the cells were counted in 25 different areas of each section.

\subsection{Statistical analysis}

SPSS software (SPSS for Windows Version 11.0) were used for for statistical analyses. One-way analysis of variance (ANOVA) and Tukey's pairwise comparisons were performed. 


\section{Results and Discussion}

\subsection{Long-term UV-A exposure disrupted} photosystem II activity

To determine how UV-A exposure affects the PS II activity, we exposed the thalli to UV-A for different durations ranging from 1 hour to $24 \mathrm{~h}$ and then measured permanent reduction in maximal PSII efficiency $(\mathrm{Fv} / \mathrm{Fm})$ to determine the rate of photoinhibition. The Fv/Fm values were significantly lower (Table 1) for $5 \mathrm{~h}$ and $24 \mathrm{~h}$ UV-exposure, indicating the photodestructive effect of UV-A on PS II after prolonged exposure.

Table 1. The results of the photosythetic quantum yield (Fv/Fm) of $P$. semipinnata thallus exposed to UV-A.

\begin{tabular}{|c|c|c|c|c|c|c|c|}
\hline & $n$ & $\begin{array}{c}\text { Control } \\
\mathbf{X} \pm \mathbf{S D}\end{array}$ & $\begin{array}{c}1 h \\
\mathrm{X} \pm \mathrm{SD}\end{array}$ & $\begin{array}{c}2 h \\
\mathrm{X} \pm \mathrm{SD}\end{array}$ & $\begin{array}{c}3 h \\
\mathrm{X} \pm \mathrm{SD}\end{array}$ & $\begin{array}{c}5 h \\
X \pm \text { SD }\end{array}$ & $\begin{array}{c}24 h \\
\mathrm{X} \pm \mathrm{SD}\end{array}$ \\
\hline $\begin{array}{l}F v / F m \\
\text { ANOVA }\end{array}$ & 10 & $0.721 \pm 0.4$ & $0.702 \pm 0.008$ & $0.708 \pm 0.017$ & $0.684 \pm 0.05$ & $0.42 \pm 0.03$ & $0.25 \pm 0.033$ \\
\hline $\begin{array}{l}\text { F ratio } \\
\text { F probability }\end{array}$ & & $\begin{array}{l}35.88 \\
0.0024\end{array}$ & & & & & \\
\hline
\end{tabular}

$\mathrm{n}=$ number of replicates, $\mathrm{x}=$ mean values, $\mathrm{SD}=$ standard deviations.

In the next step, we decided to determine if polyamine treatment would protect the cells from photoinhibition by UV-A exposure. We treated the cells with $1 \mathrm{mM} \mathrm{spd}$, spm, put or $\mathrm{H}_{2} \mathrm{O}$ and then exposed to UV-A for $24 \mathrm{~h}$. Then, we measured the permanent reduction in maximal PSII efficiency (Fv/Fm). ANOVA and Tukey post hoc test indicated that, the Fv/Fm values were significantly lower in non-treated sample compared to polyaminetreated samples (Table 2), supporting a potential protective effect of polyamines.

Table 2. Photosynthetic quantum yield (Fv/Fm) values of $P$. semipinnata exposed to UV-A light (treated by polyamines or $\mathrm{H}_{2} \mathrm{O}$ ) for $24 \mathrm{~h}$ and ANOVA results.

\begin{tabular}{lcc}
\hline Groups & $\boldsymbol{n}$ & $\mathbf{F v} / \mathbf{F m}(\mathbf{X} \pm \mathbf{S D})$ \\
\hline Control & 10 & $0.721 \pm 0.05$ \\
$\mathbf{H}_{\mathbf{2}} \mathbf{O}$ & 10 & $0.25 \pm 0.06$ \\
$\mathbf{1} \mathbf{~ m M}$ spd & 10 & $0.664 \pm 0.08$ \\
$\mathbf{1} \mathbf{~ m M}$ spm & 10 & $0.614 \pm 0.12$ \\
$\mathbf{1} \mathbf{~ m M}$ put & 10 & $0.573 \pm 0.03$ \\
& ANOVA & \\
F ratio & & 191.34 \\
F probability & & 0.0001 \\
\hline n=number of replicates, X=mean values, SD=standard \\
deviations.
\end{tabular}

\subsection{Proline content did not differ significantly in response to $U V$-A exposure}

The data showed that proline content was nearly the same in spd and spm-treated samples. It was also found that put-treated sample had higher proline content

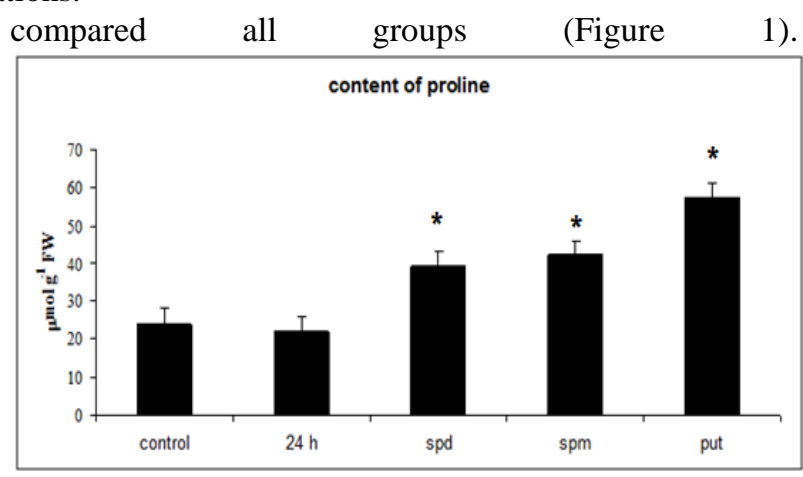

Figure 1 The proline contents of polyamine-treated samples exposed to UV-A for 24 hours. The non-treated sample indicated as $24 \mathrm{~h}$.

\subsection{Acridine orange/Ethidium bromide}

$\mathrm{AO}$ is a nucleic acid-specific ultraviolet fluorochrome which stains DNA in bright yellowish-green on a typically green cytoplasmic background. And helps to detect the healthy chromosome structure. As seen in the Figure 2, strong AO signals were detected in the unstressed or lower stressed mycobiont and phycobiont cells of $P$. semipinnata implied that there was a very low DNA damage because AO tends to combine with relatively intact DNA molecules and produced a very strong signal.

EB mixture with low concentrations of $\mathrm{AO}$ identifies normal (AO at high, EB at low fluorescence levels) and late apoptotic/necrotic (AO at low, EB at high fluorescence levels) cells. The results we obtained with $\mathrm{AO} / \mathrm{EB}$ staining revealed that number of necrotic cells significantly formed by the UV-A treatment and rate of necrotic cells of both photobiont and mycobiont layers significantly vary by the polyamine and UV-A treatments (Table 3). Both photobiont and mycobiont of $P$. semipinnata was stained as brilliant green in control, spd, spm and put-treated samples, while they were stained as brilliant orange in non-polyamine-treated samples (Figure 2). However, thallus section of the put- 
treated sample showed that UV-A affected only upper surface part of lichen thallus, especially the mycobiont layer.

One of the responses which help plants to become more tolerant to unfavorable environmental conditions is the accumulation of low molecular-weight osmolytes such as proline and polyamines (PAs). Many studies suggest that biosynthesis of PAs may be a part of the plant response mechanism [3].

Many organisms have some strategies against harmful effects of UV stress. Some researchers believe that polyamines might be one of these strategies. Although the protective role of polyamines under different environmental conditions had been widely discussed, many opinions have been put forward on its accurate mechanism. Previous studies showed that treatment of plants with spd is partially prevented the harmful effects caused by UV-radiation [4, 7]. In another study, UV light has been shown as a put accumulation stimulator in cucumber [4].Polyamines, especially the thylakoidassociated ones thought to have a constitute role of photosynthetic apparatus protection. Many researchers pointed out that polyamine accumulation in cucumber leaves is an adaptive mechanism against the UVradiation stress. Lütz et al. [8] demonstrated the change of polyamine content under UV-light treatment in tobacco. Out of this study, Kotzabasis et al. [5] demonstrated the relation between Light Harvesting Complex (LCH) and PSII and polyamines. In our previous study we showed the protective effects of exogenously added polyamines on $\mathrm{Fv} / \mathrm{Fm}$ under UV-A stress in lichens [7]. Similarly, in our present work, Fv/Fm did not cause sharply decline in the samples that treated with spd and spm after UV-A radiation exposure for $24 \mathrm{~h}$. These results can be interpreted as that the polyamines protect the photosystem II from UV-A radiation (Table 1) [7]. The main question is if polyamines protect whole lichen thalli or only photobiont layer in lichen thalli under UV-A stress. In the present study, we have tried to understand that effect of polyamines on osmoprotectant production such as proline in whole thalli and protective role against cellular damage in both mycobiont and photobiont layer under UV-A radiation.

Proline has been assigned the role of a cytosolute, a storage compound or protective agent for cytoplasmic enzymes and cellular structure [9]. In addition, Alia et al. [10] reported that the UV-induced proline accumulation protects the plants against UV-promoted peroxidative stress. Therefore, the increased proline concentration may act as a hydroxyl radical and singlet oxygen scavenger [11]. However, in the present study, UV-A exposure was not significantly affected on proline accumulation in non-polyamine-treatment groups compared with the control group. Interestingly, polyamine-treated samples showed that proline content were significantly higher than control group, however, especially put significantly induced proline production compare to other polyamine-treated samples (Figure 1). Similarly, Wang et al [12] demonstrated the increase level of proline after spd or spm addition in Nymphoides peltatum leaves under copper stress. Duan et al [13] also showed that exogenous spd addition to the medium increased proline amount in cucumber roots under salt stress. One suggestion about the relationship between polyamine and proline as a substrate-product complex [14]. Moreover, polyamines and proline synthesis were not only require common precursors which are glutamate, arginine, and ornithine, but also polyamine metabolisms could be related to expression of gene for proline biosynthetic enzymes [15]. Therefore, polyamines induced the accumulation of free proline to protect against oxidative damage [16]. Similarly, in the present study, exogenous polyamine induce proline accumulation, it could be help to protection from UV-A stress.

Photosynthetic organisms exposure to high level of UV radiation causes an oxidative stress resulting in chlorophyll degradation and necrosis. DNA is also one of the most notable targets of UV-radiation. Previous studies showed that UV-A-induced cytotoxicity and oxidative damage depend on radiation intensity and dose distribution [17]. In our previous study we also demonstrated the affected DNA template activity via DNA structural damage [18]. Cellular DNA damage occurs by both the direct and indirect effects of ultraviolet radiation. Indirectly, DNA strand break is induced by the attack of the bases via hydroxyl radical. Previous studies demonstrated the protection effect of polyamines on hydroxyl radical- induced DNA strand breaks [19]. At physiological pH, the spm, spd and put are found as polyammonium ions. Since polycations serve to stabilize active oxygen radicals DNA damage is inhibited via scavenging of these active radicals [19]. This hypothesis is supported by the significantly negative relationship between rate of necrotic cell and the external polyamine application in thalli of $P$. semipinnata (Table 3, Figure 2).

Table 3. Necrotic cell rates of $P$. semipinnata exposed to UV-A light (treated with polyamines or $\mathrm{H}_{2} \mathrm{O}$ ) for $24 \mathrm{~h}$ and results of the ANOVA between treatments.

\begin{tabular}{lcc}
\hline Groups & $\boldsymbol{n}$ & $\begin{array}{c}\text { necrotic cells\% } \\
\boldsymbol{X} \pm \boldsymbol{S D}\end{array}$ \\
\hline control & 25 & $5.03 \pm 1.21$ \\
$\mathbf{H}_{\mathbf{2}} \mathbf{O}$ & 25 & $84.2 \pm 6.10$ \\
$\mathbf{1} \mathbf{~ m M}$ spd & 25 & $15.3 \pm 0.61$ \\
$\mathbf{1}$ mM spm & 25 & $37.0 \pm 4.60$ \\
$\mathbf{1}$ mM put & 25 & $48.7 \pm 5.70$ \\
& ANOVA & \\
F ratio & & 146,29 \\
F probability & & 0,000 \\
\hline
\end{tabular}

$\mathrm{x}=$ mean values, $\mathrm{SD}=$ standard deviations. 


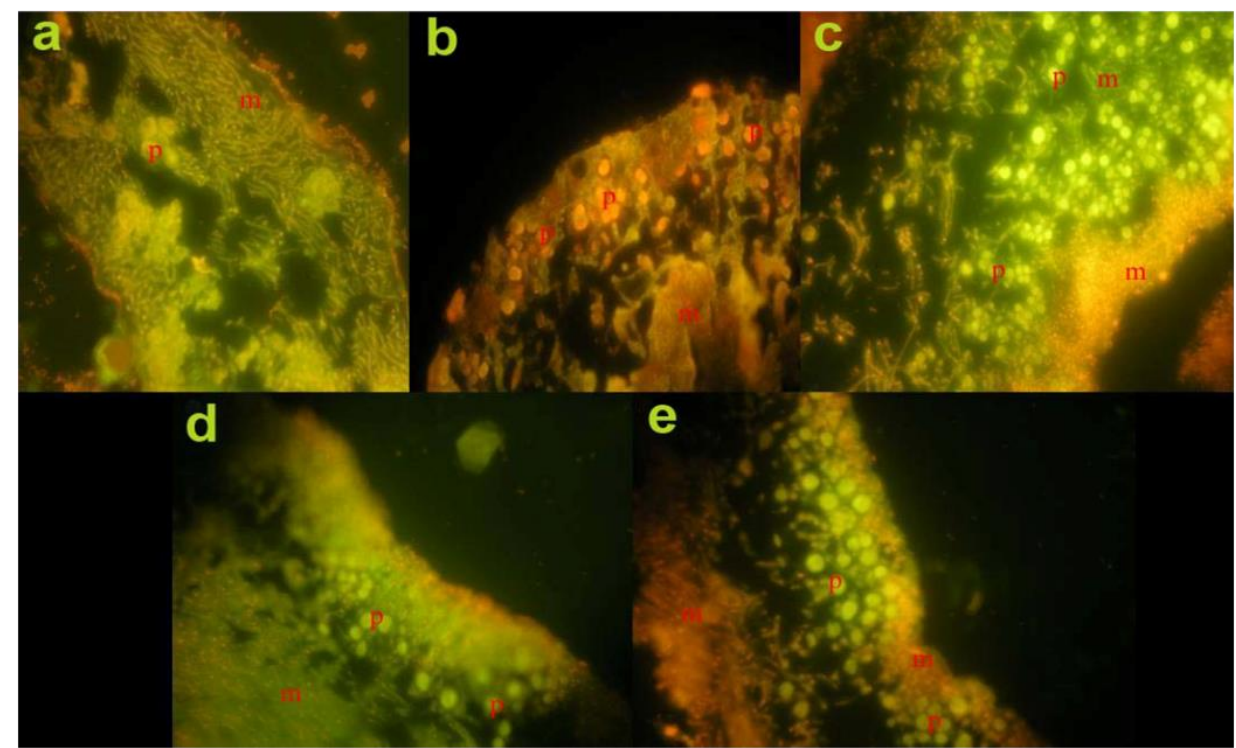

Figure 2. Acridine orange/Ethidium bromide staining of the lichen cross-sections; control group (a), UV-A exposed sample for $24 \mathrm{~h}$ (b), spd-treated sample (c), spm-treated sample (d), put-treated sample (e), m: mycobiont layer, p: phycobiont layer.

Solheim et al. [20] mentioned the remarkable tolerance of lichens to extreme radiation conditions, on the contrary to terrestrial plants. Correlatively, short term (1 $\mathrm{h}, 2 \mathrm{~h}$, and $3 \mathrm{~h}$ ) UV-A exposure didn't changed the Fv/Fm ratio in $P$. semipinnata, in our present study. However, when $P$. semipinnata thalli were exposed to UV-A irradiation for $5 \mathrm{~h}$ and $24 \mathrm{~h}$, the results showed the highest damage. It is known that the maximum $\mathrm{Fv} / \mathrm{Fm}$ rate is a sign of high light and radiation exposure [18]. For this reason, Fv/Fm rate is usually accepted as an indicator of photoinhibition. Under normal conditions, the Fv/Fm value of lichens varies between 0.45-0.65.

In the present study, 0.47 and $0.15 \mathrm{Fv} / \mathrm{Fm}$ values indicated the harmful effects of UV-A on photosystem II. These results indicate that the susceptibility or tolerance against UV-A radiation may depend on the exposure time. In the present study, fluorescence staining of $P$. semipinnata thalli demonstrated that UVA radiation cause necrosis formation (Figure 2).

Relatively strong AO signals were detected in the unstressed or lower stressed mycobiont and phycobiont cells of $P$. semipinnata indicates a low degree of DNA damage. AO tends to bind incorrupt DNA strands with a strong signal. While EtBr with low concentrations of AO identifies normal and late apoptotic/necrotic cells. $\mathrm{EtBr}$ staining reflects the density of necrotic cells. Decreased AO staining may be related to destruction of DNA molecules into small fragments. In this study, the $\mathrm{AO} / \mathrm{EtBr}$ staining process showed that the number of necrotic cells significantly modified by the UV-A treatment (Figure 2). However, the spd and spm-treated samples showed the lower percentage of necrotic cells than the untreated samples, in the mycobiont layer of untreated ones showed an increased level of necrotic cells at higher UV-A exposure.

\section{Conclusion}

In summary, we have analyzed the changes of photosynthetic efficiency, proline content, and necrosis in lichen thallus during UV-A stress and have demonstrated the protection of polyamines against UVA induced oxidative damage.

As a result, we demonstrated the increase of proline amount after external polyamine treatment (especially the put) in the cell during UV-A exposure. Since proline has an important role as a hydroxyl radical and singlet oxygen scavenger, the increased concentration of proline in $P$. semipinnata cells, might enhanced the tolerance against UV-A stress.

\section{References}

1. Strid, AW, Chow, WS, Anderson, JM, UV-B damage and protection at the molecular level in plants, Photosynthesis Research, 1994, 39, 475-489.

2. Riegger, L, Robinson, D, Photoinduction of UV-absorbing compounds in Antarctic diatoms and Phaeocystis antartica. Marine Ecology Progress Series, 1997 160, 13-25.

3. Bouchereau, A, Aziz, A, Larher, F, Martin-Tanguy, J, Polyamines and environmental challenges, recent development, Plant Science, 1999 140, 103-125.

4. Kramer, GF, Norman, HA, Krizek, DT, Mirecki, RM, Influence of UV-B radiation on polyamines, lipid peroxidation and membrane lipids in cucumber, Phytochemistry, 1991, 30, 21012108 .

5. Kotzabasis, K, Fotinou, C, Roubelakis-Angelakis, KA, Ghanotakis, D, Polyamines in the photosynthetic apparatus, Photosystem II highly resolved subcomplexes are enriched in spermine, Photosynthesis Research, 1993, 38, 83-88. 
6. Bates, LS, Waldren, RP, Tear, ID, Rapid determination of free proline for water-stress studies, Plant Soil, 1973, 39, 205-207.

7. Unal, D, Tuney, I, Sukatar, A, The role of external polyamines on photosynthetic responses, lipid peroxidation, protein and chlorophyll $a$ content under the UV-A (352 nm) stress in Physcia semipinnata, Journal of Photochemistry and Photobiology B, 2008, 90, 64-68.

8. Lütz, C, Navakoudis, E, Seidlitz, HK, Kotzabasis, K, Simulated solar irradiation with enhanced UV-B adjust plastid-and thylakoid-associated polyamine changes for UV-B protection, Biochimica et Biophysica Acta-Bioenergetics, 2005, 1710, 24-33.

9. Demir, Y, Growth and proline content of germinating wheat genotypes under ultraviolet light, Turkish Journal of Botany, 2000, 24, 67-70.

10. Alia, P, Mohanty, P, Matysik, J, Effect of proline on the production of singlet oxygen, Amino Acids, 2001, 21, 195-200.

11. Smirnoff, N, Cumbes, QJ, Hydroxyl radical scavenging activity of compatible solute, Phytochemistry, 1989, 28, 1057-1060.

12. Wang, $\mathrm{X}, \mathrm{Shi}, \mathrm{G}, \mathrm{Xu}, \mathrm{Q}, \mathrm{Hu}, \mathrm{J}$, Exogenous polyamines enhance copper tolerance of Nymphoides peltatum, Journal of Plant Physiology, 2007, 164, 1062-70.

13. Duan, JJ, Li, J, Guo, SR, Kang, YY, Exogenous Spermidine affects polyamine metabolism in salinity-stressed Cucumis sativus roots and enhances short-term salinity tolerance, Journal of Plant Physiology, 2008, 165, 1620-35.

14. Aziz, A, Martin-Tanguy, J, Larher, F, Stress-induced changes in polyamine and tyramine levels can regulate proline accumulation in tomato leaf discs treated with sodiumchloride, Physiologia Plantarum, 1998, 104, 195-202.
15. Tanou, G, Ziogas, V, Belghazi, M, Christou, A, Filippou, P, Job, D, Fotopoulos, V, Molassiotis, A, Polyamines reprogram oxidative and nitrosative status and the proteome of citrus plants exposed to salinity stress, Plant Cell and Environment, 2014, $37,864-885$

16. Kumar, SG, Mattareddy, A, Sudhakar, $\mathrm{C}, \mathrm{NaCl}$ effects on proline metabolism in two high yielding genotypes of mulberry (Marus alba L.) with contrasting salt tolerance, Plant Science, 2003, 165, 1245-1251.

17. Hoerter, ID, Arnold, AA, Kuczynska, DA, Shibuya, A, Ward, CS, Sauer, MG, Effects of sublethal UVA irradiation on activity levels of oxidative defense enzymes and protein oxidation in Escherichia coli, Journal of Journal of Photochemistry and Photobiology B, 2005, 81, 171-180.

18. Unal, D, Tuney, I, Esiz-Dereboylu, A, Sukatar, A, The effect of UV-A (352 nm) stress on chlorophyll fluorescence, chlorophyll a content, thickness of upper cortex and determinate DNA damage in Physcia semipinnata, Photochemistry and Photobiology, 2009, 94, 71-76.

19. Oh, TJ, Kim, IG, Polyamines protect against DNA strand breaks and aid cell survival against irradiation in Escherichia coli, Biotechnology Techniques, 1998, 12, 755-758.

20. Solheim, B, Zielke, M, Bjerke, JW, Rozema, J, Effects of enhanced UV-B radiation on nitrogen fixation in arctic ecosystems, Plant Ecol, 2006, 182, 109-118. 